\title{
Argument map for carbon capture and storage
}

\author{
Sander van Egmond ${ }^{\mathrm{a}, *}$, Marko P. Hekkert ${ }^{\mathrm{b}}$ \\ ${ }^{a}$ Utrecht Sustainability Institute, Utrecht University, Willem C. van Unnikgebouw, Heidelberglaan 2, 3584 CS Utrecht, The Netherlands \\ b Copernicus Institute of Sustainable Development, Utrecht University, P.O. Box 80115, 3508 TC Utrecht, The Netherlands
}

\section{A R T I C L E I N F O}

\section{Article history:}

Received 13 March 2012

Received in revised form 14 August 2012

Accepted 22 August 2012

Available online $\mathrm{xxx}$

\section{Keywords:}

$\mathrm{CO}_{2}$ capture and storage

Public discourse

Arguments

Validity

CCS chain

\begin{abstract}
A B S T R A C T
Carbon capture and storage (CCS) can contribute to the deep $\mathrm{CO}_{2}$ cuts which are necessary to achieve climate change targets. There is, however, a strong public debate whether CCS should be implemented. In this article we give an overview of the arguments for and against based on the opinion of Dutch stakeholders. CCS is an umbrella term for a wide range of different configurations of separate technologies. Some arguments are applicable in general for all CCS chains; some are only valid for a particular configuration. In this paper we will discuss these arguments in the context of the background of different CCS configurations. The argument that CCS costs a lot of extra energy, for instance, is valid for the power sector, not for gas treatment. A good understanding of the CCS debate and the arguments used may help with developing a better energy policy and may give direction to future research and technology development.
\end{abstract}

Crown Copyright (c) 2012 Published by Elsevier Ltd. All rights reserved.

\section{Introduction}

It is widely accepted that burning fossil fuels contributes to climate change. Governments have agreed that the global temperature may not rise more than $2{ }^{\circ} \mathrm{C}$ compared to pre-industrial levels, as has recently been reconfirmed in the UN Cancun climate summit (UNFCCC, 2011). This target implies a maximum concentration of 450 parts per million (ppm) $\mathrm{CO}_{2}$ in the atmosphere. This requires deep cuts in carbon emissions and therefore a transformation of our energy system towards a low carbon energy system. Carbon capture and storage (CCS) can be one of the mitigation options to achieve the necessary deep cuts in $\mathrm{CO}_{2}$ emissions.

Unfortunately, CCS is a contested technology; it is highly discussed in the public media by different societal groups who have diverse visions and expectations regarding CCS. For some, CCS is the technology that we need to combat climate change while others see it as a technology that prevents a real transformation to a sustainable energy system. However, for CCS to be applied at a large scale, public support is necessary, and the lack of public support severely reduces the chance of success of this new technology (IEAGHG, 2010). For instance, the public debate on nuclear energy in the Netherlands and Nordic countries has resulted in a ban on new nuclear power plants (Arentsen, 2006). In the Netherlands there has been a strong debate on a $\mathrm{CO}_{2}$ storage project under the Barendrecht town as well. This debate ultimately resulted in

\footnotetext{
* Corresponding author. Tel.: +31 30 2537641; fax: +31 302531145

E-mail address: s.vanegmond@uu.nl (S. van Egmond).
}

the cancellation of the project and other CCS onshore plans in the Netherlands.

When a technology is contested and public debates are taking place, often a wide variety of arguments in favour of and against the new technology are used. For the CCS community it is important to have insight in the arguments that may be used in the public debate as these arguments influence public opinion. With sufficient information about the arguments used, the CCS community may influence the public debate more effectively. The CCS technology is not static and some drawbacks can be overcome with new technologies and new knowledge. An analysis of the arguments can also aid policy makers to make better founded decisions. In the scientific papers often only a few arguments are discussed, e.g. the environmental impact of CCS, costs or public perception. In the ACCEPT project a more integrated approach was chosen. Twelve critical questions on CCS were asked and analysed, before the authors came to the conclusion that the implementation of CCS would be advisable (De Coninck et al., 2009).

The public debate on CCS is influenced by the fact that CCS does not represent a single technology. Actually, CCS is an umbrella term for a wide range of different configurations of separate technologies which constitute a specific chain when they are combined with each other. A conceptual diffuseness about what CCS actually entails might make the discourse on CCS confusing and sub-optimal, as advocates and opponents of the technology may implicitly have very different technological configurations in mind that are partly responsible for their difference in opinion. So whereas several arguments are applicable in general for all CCS chains, some are only valid for a particular configuration. In this 


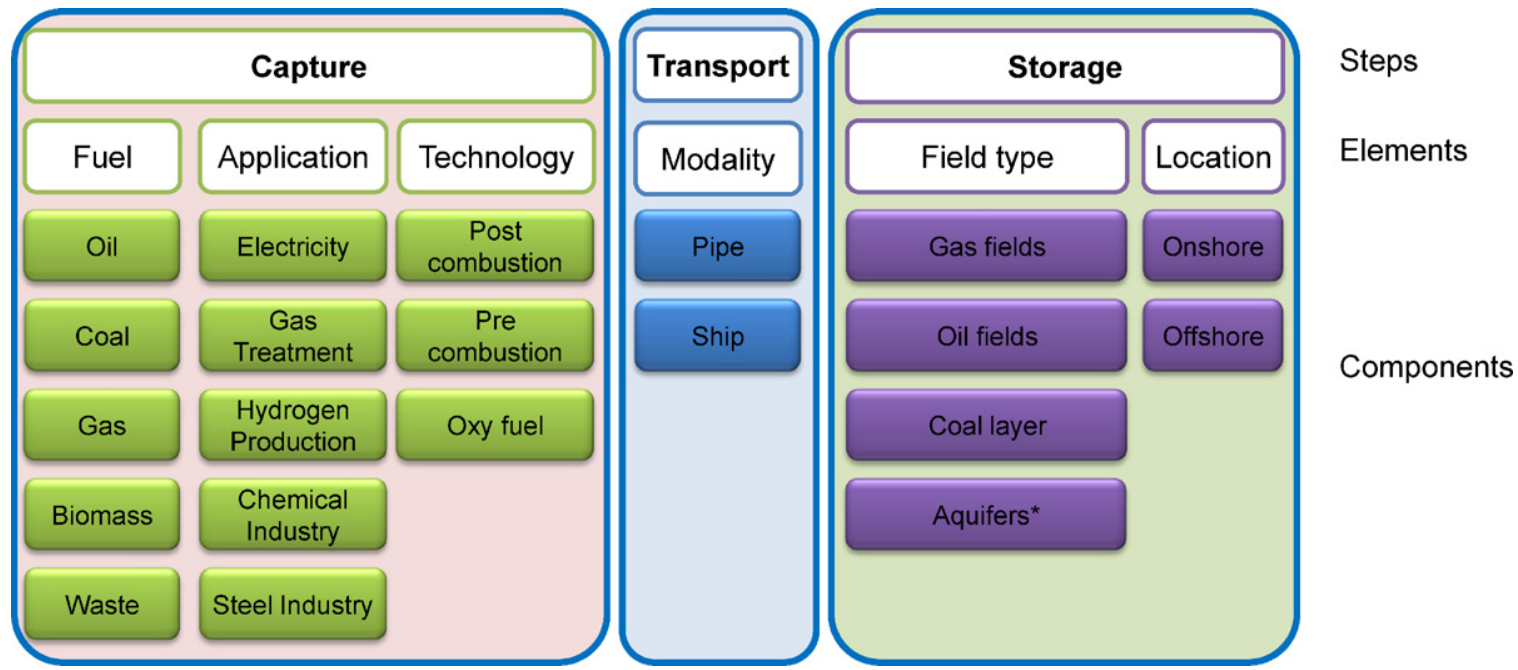

Fig. 1. The different steps, elements and components of CCS. *Non-potable and non-economic water.

study we will discuss the arguments in the context of different CCS configurations. We will for example show that the debate is different when CCS is applied at coal fired power stations compared to refineries. Arguments on safety, for example, also differ for onshore versus offshore storage.

In this article we present the arguments pro and con CCS that are used by stakeholders in the Netherlands. By presenting these arguments concisely and clearly, we hope to contribute to a higher quality of the debate. The arguments are visualised in a so called 'argument map' (Argumentenfabriek, 2010a). Experience with other topics, such as nuclear energy and adaption of the retirement age, has shown that translating complex topics into such a compact graphical representation helps people to obtain a betterinformed opinion. In general, this results in a more balanced view for both advocates and opponents as well as in a higher quality of the debate (Argumentenfabriek, 2010b).

We will therefore identify the arguments used in the societal and academic discourse and link these views with the different possible configurations of CCS. Additionally, the scope of arguments is discussed. First, the scope of the arguments for the different components of CCS is analysed, as some are generic, whereas others only apply to specific chains. Second, the applicability for the Netherlands is examined. In doing so we aim to understand whether and how the public debate is influenced by implicit ideas about technological designs and how future public discourses can be enlightened by a better and shared definition of the debated technology.

\section{Different components in the CCS chain}

In the public discourse on CCS arguments are used that refer to different dimensions of CCS projects. Hence, it is necessary to first conceptually deconstruct CCS into different components. A critical follower of CCS once called CCS a many headed monster since each different configuration has its own disadvantages (De Jong, 2010). Advocates of CCS may on the other hand claim that CCS resembles a Swiss army multi-tool with a different CCS configuration for each specific problem.

It is therefore essential to make this distinction in order to accurately discuss all potential configurations of CCS and the scope of the arguments. The CCS chain consists of three steps, namely capture, transport and storage. Each step has one or more elements and each element contains several components, as presented in Fig. 1.
We define an integrated CCS project as the configuration made up of all three steps and with at least one component for each element.

For example the capture step in Shell's proposed Barendrecht project in the Netherlands is done with the fuel (natural) gas, in a hydrogen production application with pre-combustion capture technology. The $\mathrm{CO}_{2}$ is then transported by pipe line. In the final storage step the $\mathrm{CO}_{2}$ is stored in a gas field (field type) at an onshore location.

\section{First step: capture}

Below we will describe the components of the first step in the CCS chain, the capture of $\mathrm{CO}_{2}$.

Element: fuel

The fuel is the input for the energy conversion process (the application). The origin of the carbon in the fuel that needs to be captured may be either fossil or biomass. The emission of $\mathrm{CO}_{2}$ per energy unit varies depending on its source. The $\mathrm{CO}_{2}$ emission factor of natural gas is about $50 \mathrm{~kg} \mathrm{CO} / \mathrm{GJ}, 70 \mathrm{~kg} \mathrm{CO} / \mathrm{GJ}$ for oil and $95 \mathrm{~kg} \mathrm{CO} / \mathrm{GJ}$ for coal. When coal is burned therefore almost double the $\mathrm{CO}_{2}$ per energy unit is emitted compared to natural gas (IPCC, 2005). Thus, the effect of CCS greatly depends on the fuel type. When biomass is used, the net emission towards the atmosphere is close to zero. In other words, storing $\mathrm{CO}_{2}$ after conversion of biomass into useful energy results in a carbon sink, also labelled as negative carbon emissions. Waste is often a combination of biomass, like wood, crop and food residues and fossil fuels that are part of plastics as feedstock.

Element: application

The focus of CCS is on capturing $\mathrm{CO}_{2}$ at large stationary sources since these are the most suitable for CCS on the short and midterm (IPCC, 2005). There are many processes that convert primary energy into useful products. Each process emits $\mathrm{CO}_{2}$ in different concentrations and at a different pressure. This strongly determines the possible $\mathrm{CO}_{2}$ capture processes and for example the energy needed to retain high concentrations $\mathrm{CO}_{2}$. The carbon concentration in flue gases of a gas fired power plant is about 3-7\% whereas the concentration for coal fired power plants is much higher (14\%), making $\mathrm{CO}_{2}$ capture of coal fired power plants cheaper per tonne of $\mathrm{CO}_{2}$, compared to gas fired power plants. However, the total $\mathrm{CO}_{2}$ emitted by a coal plant per $\mathrm{kWh}$ is almost double compared to a gas fired power plant, and thus it needs to capture almost double the amount of $\mathrm{CO}_{2}$. The concentration of $\mathrm{CO}_{2}$ in flue gases of steel plants is higher than for power plants (up to 27\%) (IPCC, 2005). At facilities where ammonia and/or hydrogen is made, $\mathrm{CO}_{2}$ at high concentrations is produced as a by-product. Natural gas that is produced from 
Table 1

General characteristics of the four field types of storage locations prior to the start of a storage project for Dutch case.

\begin{tabular}{|c|c|c|c|c|c|}
\hline Mainly relevant for & Issue & $\begin{array}{l}\text { (Nearly) empty gas } \\
\text { fields }\end{array}$ & Oil fields & Coal layers & Aquifers $^{c}$ \\
\hline Safety & Gastight & $\begin{array}{l}\text { (Virtually) proven on } \\
\text { geological timescale }\end{array}$ & Sometimes proven & Sometimes proven & Unknown \\
\hline Safety & Existing wells & Few & Many & None-many ${ }^{\mathrm{b}}$ & None-many ${ }^{\mathrm{d}}$ \\
\hline Safety & $\begin{array}{l}\text { Pressure compared } \\
\text { with surroundings }\end{array}$ & Much lower ${ }^{\mathrm{a}}$ & About equal & Equal or higher & About equal \\
\hline Safety/economics & $\begin{array}{l}\text { Geological } \\
\text { knowledge of } \\
\text { location }\end{array}$ & Large & Large & Little & Medium \\
\hline Economics & $\begin{array}{l}\text { Extra economic } \\
\text { benefits }\end{array}$ & $\begin{array}{l}\text { None, in some cases extra } \\
\text { natural gas }\end{array}$ & Oil production & Natural gas production & None \\
\hline Economics & $\begin{array}{l}\text { Economic risk that } \\
\text { injection does not } \\
\text { go according to } \\
\text { plan }\end{array}$ & Low & Low & Higher & Medium \\
\hline
\end{tabular}

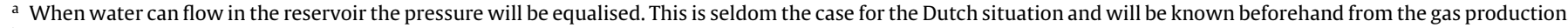

b Depending on whether the layer is used for natural gas production (CBM).

c Non-potable and non-economic water.

d Depending on whether oil or gas fields below the aquifer are used for production.
}

a subsurface reservoir can contain $\mathrm{CO}_{2}$. When the natural $\mathrm{CO}_{2}$ concentration is too high, the $\mathrm{CO}_{2}$ must be removed to meet the proper specifications. With this natural-gas sweetening process, it is often also possible to obtain high concentrations $\mathrm{CO}_{2}$ at high pressure. These high $\mathrm{CO}_{2}$ concentration flows do not need expensive and energy consuming separation techniques and they therefore have a positive influence on the economics and energy balance of CCS (IPCC, 2005).

Element: capture technology

There are three main approaches to $\mathrm{CO}_{2}$ capture. The first is post-combustion, where the $\mathrm{CO}_{2}$ is separated from the flue gases. This is typically done with chemical solvents. With pre-combustion systems the fuel is transformed into a mixture of $\mathrm{H}_{2}$ and $\mathrm{CO}_{2}$. This gas is then separated into almost pure hydrogen and $\mathrm{CO}_{2}$. The last approach is oxy-fuel combustion, which is also referred to as denitrogenated combustion. This process uses oxygen instead of air for combustion of the fuel, producing mainly $\mathrm{CO}_{2}$ and $\mathrm{H}_{2} \mathrm{O}$. After condensation of the steam in this oxy-fuel process, a highly concentrated $\mathrm{CO}_{2}$ stream is obtained (IPCC, 2005). The concentration of the captured $\mathrm{CO}_{2}$ depends on the process; for power plants it varies between 95 and 99.9\% (IPCC, 2005).

For electricity production all of the above combinations of fuel and capture technology can be made. Ammonia and hydrogen are produced using technology that is very similar to the precombustion process. With natural gas sweetening no energy is converted, so no combustion takes place. The process is, however, comparable with post- combustion capturing, but at high pressures and under the absence of $\mathrm{NO}_{X}$ (IPCC, 2005).

\section{Second step: transport}

Before $\mathrm{CO}_{2}$ is transported, it is compressed to reduce the volume and increase the density of $\mathrm{CO}_{2}$. Commercial-scale transport uses pipelines or ships for gaseous and liquid carbon dioxide. For transport by ship temporary storage and loading facilities onshore are needed. Ship transport is seen as more flexible compared to pipelines as shipping routes can change and pipeline traces cannot. However, transport by ship is not always possible onshore since there are not always rivers or canals available close to onshore storage sites. Ship transport becomes cost-competitive with pipeline transport over a large distance. The breakeven point shifts towards pipelines at larger quantities (IPCC, 2005).

\section{Third step: storage}

\section{Element: field type}

$\mathrm{CO}_{2}$ can be stored in (nearly) empty gas fields, oil fields, coal layers or aquifers. The appropriateness of a subsurface storage location depends on many factors. Each location has its own characteristics with their pros and cons. At the 10th International Conference on Greenhouse Gas Control Technologies, GHGT10, the phrase "nothing is as unique as a storage site" was often mentioned (De Vos and van Egmond, 2010). The Dutch aquifers that might be considered for $\mathrm{CO}_{2}$ storage contain brine, so water in the aquifer is not potable and has no economic value.

However, we try to make a general comparison between different types of reservoirs, as summarised in Table 1 . When dealing with $\mathrm{CO}_{2}$ storage we see two types of risks involved for all storage sites. The first risk entails that the $\mathrm{CO}_{2}$ storage capacity or the injection rate is smaller than expected. This is an economic risk for the company that wants to store the $\mathrm{CO}_{2}$. For example, if the injectivity turns out to be lower than forecasted, the $\mathrm{CO}_{2}$ injection rate cannot be achieved. If this situation occurs, it may be possible to drill extra injection wells. Of course, this will add to the total cost of the project. It is also possible that the total capacity is lower than estimated in advance, resulting in an economic setback. From Table 1 it becomes clear that gas and oil fields have in general the lowest economic risk. As gas and oil fields have been used for production, an enormous amount of data of the reservoirs has been generated. With this knowledge it is possible to make in depth models of the reservoir. These models can predict the $\mathrm{CO}_{2}$ flow through the reservoir and therefore calculate how much $\mathrm{CO}_{2}$ can be injected. The economic risk is therefore smaller than when aquifers or coal layers are used.

The second risk is a safety risk, and revolves around the possibility that stored $\mathrm{CO}_{2}$ may escape to the surface. The presence of gas in the reservoir is a strong indication that the reservoir is gastight. When these fields will be used for $\mathrm{CO}_{2}$ storage they will be (almost) empty. This means, in the Dutch situation, that the pressure inside the reservoir can be up to hundreds of bars lower than the surrounding rocks. The injected $\mathrm{CO}_{2}$ will partly remove this relative vacuum. Even if there might be a leakage of the reservoir, water from outside the reservoir will migrate inwards rather than the $\mathrm{CO}_{2}$ outwards. This is a strong advantage of gas fields, as it renders them relatively safe. In some oil fields also natural gas is found, giving a strong indication for a good seal. However, there are also many oil fields that do not contain natural gas (anymore). For those oil fields it is thus more difficult to prove that they are gastight. This is also the case for aquifers and coal layers. As said before, these are some general considerations. A good site characterisation is always necessary to determine the quality of the seal.

As depleted natural gas and oil fields have been used for production, they contain wells. These wells can be reused for injection, providing an economic advantage. Unfortunately, the injection 
Table 2

A selection of the (proposed) Dutch CCS projects split according to the defined components.

\begin{tabular}{|c|c|c|c|c|c|c|}
\hline Project & Fuel & Application & Technology & Transport & Field type & Location \\
\hline Barendrecht (Shell) & Oil/gas & Refinery & Pre combustion & By pipe & Gas field & Onshore \\
\hline Geleen (DSM Agro) & Gas & Ammoniac production & Pre combustion & On own site & Aquifer & Onshore \\
\hline MAGNUM NUON & Gas and coal & Electricity production & Pre combustion & By pipe & Gas field & Onshore \\
\hline $\mathrm{K} 12 \mathrm{~b}$ & Gas & Gas treatment & Post combustion & On own site & Gas field EGR ${ }^{\mathrm{a}}$ & Offshore \\
\hline ROAD (E.On \& Electrabel) & Coal + biomass & Electricity production & Post combustion & By pipe & Gas field & Offshore \\
\hline Essent/RWE North NL & Coal & Electricity production & Post combustion & By pipe & Gas field & Onshore \\
\hline SEQ Drachten $^{c}$ & Gas & Electricity production & Oxy fuel & By pipe & Gas field EGR ${ }^{\mathrm{a}}$ & Onshore \\
\hline Tata Steel & Coal & Steel & Oxy fuel & & & \\
\hline Twence & Waste & Electricity production $^{\mathrm{d}}$ & Post combustion & & & \\
\hline Air Liquide Rozenburg & Gas & $\mathrm{H}_{2}$ production & Pre combustion & Pipe/ship & $\mathrm{EOR}^{\mathrm{b}}$ & Offshore ${ }^{\mathrm{e}}$ \\
\hline
\end{tabular}

CATO (2011).

Open cells indicate that the total configuration has not been decided yet.

a Enhanced gas recovery.

b Enhanced oil recovery.

c Scope and name of the project have changed several times. Currently the project name is Pegasus and it aims to use low caloric natural gas with high $\mathrm{CO}_{2}$ concentrations for power generation. The use of pure oxygen should prevent gas treatment.

d Waste burning with electricity production, this application is not mentioned in Fig. 1 as it is too specific.

e Oil fields in Danish territorial part of the North Sea.

wells and abandoned wells are also seen as the most probable leakage pathways for $\mathrm{CO}_{2}$ storage projects (IPCC, 2005).

Old wells therefore need to be abandoned in a proper way, to avoid potential $\mathrm{CO}_{2}$ leakage during future use. A proposed project in the Netherlands near the town De Lier was cancelled as no certainty could be given about the safety of an old abandoned well. Due to building developments this particular well could not be reached for inspection or adaptation (FD, 2007). Some aquifers also have wells, when oil or gas drillings have been carried out in potential fields below the aquifer. In that case the well penetrates the aquifer. If that is not the case, all the wells can be designed specifically for $\mathrm{CO}_{2}$ storage.

Finally it is interesting to note that the injection of $\mathrm{CO}_{2}$ in oil fields and coal layers can result in more oil or natural gas respectively. This Enhanced Oil Recovery process is being used in the US and Canada since many decades.

Element: Location

For the properties of the subsurface reservoir it is not relevant whether it lays onshore or offshore. However, storing $\mathrm{CO}_{2}$ onshore is in general less expensive than offshore. IPCC (2005) estimates that in Europe the cost for onshore is $1.7 \$ /$ tonne $\mathrm{CO}_{2}$ stored, whereas offshore the cost is $6.0 \$ /$ tonne $\mathrm{CO}_{2}$ stored. Another important difference is the (perceived) risk for humans and the environment.

\section{Dutch CCS chains}

Based on Fig. 1, an enormous amount of different CCS configurations can be defined. There are for example 5 different fuel types for power plants and 3 different capture technologies, resulting in 15 capture configurations for power plants. Moreover, the $\mathrm{CO}_{2}$ can be transported in two different ways and stored in four different types of reservoirs, both onshore and offshore, resulting in 240 different configurations for CCS in the electricity sector. For the other sectors the variety is less, since not all configurations are possible or logical. Natural gas treatment, for example, is done with natural gas with post-combustion technology. We estimate that there are around 500 different CCS chains that can be considered logical based on the components in Fig. 1.

In the Netherlands a dozen CCS projects have been proposed, as summarised in Table 2. Until now the only one that has been realised is the offshore gas treatment K12-B project. This project started injection in 2004 and is operated by Gaz de France-Suez. As can be seen from the table, many different configurations of CCS are proposed. Some of the projects have already been withdrawn. In the Dutch situation the emphasis lies on using gas fields for storage.

\section{Argument map}

Thus, different configurations of CCS chains have different advantages and disadvantages. Each concrete CCS project therefore has its own set of arguments pro and contra. However, when discussing a single argument without reference to a concrete project, generally there is no interaction between the several elements. For instance, the origin of $\mathrm{CO}_{2}$, the application and the capture process are not relevant for an argument on the safety of transport. That is why we have constructed a general map with all relevant arguments for all foreseeable Dutch cases. A similar map designed for a concrete CCS project would contain fewer arguments.

To generate an inventory of all possible arguments we combined several sources of information. These included the analysis of the arguments used in the Dutch media (Kliest, 2010). The list was completed with opinions of both opponents and advocates of CCS (Greenpeace, 2008; Nackenhorst et al., 2009; Vosbeek and Warmenhoven, 2007). This background material was given to a consultant company specialised in gathering and grouping arguments. They led two workshops with eight different experts to complete the list even further. The choice was made to work with independent but well informed outsiders (who did not belong to the CCS community) to ensure extra openness and objectivity.

Before the workshop first the central question was defined: "What are the arguments for or against CCS in the Netherlands?" Due to the focus on the Netherlands, several CCS options were left out. For instance, deep ocean storage is not considered, as the North Sea is too shallow for storage of $\mathrm{CO}_{2}$ in the sea water. Secondly we took climate objectives for granted. For example, $\mathrm{CO}_{2}$ emissions must be $80 \%$ lower in 2050 compared to 1990 . Therefore arguments questioning climate change and/or the necessity for $\mathrm{CO}_{2}$ reductions were not considered.

During the first expert workshop two brainstorm sessions, one collecting arguments for and the other gathering arguments against, were held to generate as many arguments as possible. Each participant had to write down all the arguments they could think of. The opinion of the participants of the workshops varied from against to neutral to in favour of CCS. The participants were quite capable of mentioning arguments that did not necessarily support their own opinion. Thus, advocates of CCS also referred to arguments against CCS, and vice versa.

When the participants had finished their own inventory, arguments were collected during several rounds. Each person was only allowed to give one new argument during each round, to ensure that all participants could contribute equally. Furthermore, since arguments were projected on a screen, the other participants could 
improve upon the argument if they were of the opinion that the argument was factually incorrect. However, they were not allowed to discuss or refute an argument simply because of disagreement. After a dozen rounds all the arguments had been collected.

After this workshop the arguments were grouped into themes and checked for completeness with the original list. During the second workshop the different themes were discussed as well as the relevance of the arguments and their completeness.

This resulted in 57 arguments, 31 con and 26 pro (see Fig. 2). The arguments were divided into six themes:

- Climate

- Energy

- Environment

- Ethics

- Safety

- Economics

As we refer to an argument 'map', the different themes are called districts. Each district has pros and cons, and within districts arguments are grouped into a total of 21 neighbourhoods. An individual argument is referred to as a street.

It is important to note that the presented arguments do not cover the whole CCS debate. The arguments presented are seen as valid by the experts. A statement of a worried inhabitant "I just do not want $\mathrm{CO}_{2}$ under my backyard", is a valid opinion, but not an argument. In the map this example is transformed to the ethical argument: " $\mathrm{A}$ solution that has little public support is not acceptable."

Nomenclature for arguments of Fig. 2.

$1-2-3-4$

1st themes: climate, energy, environment, ethics, safety or economics (district).

2nd attitude: for or against.

3rd group of arguments (A, B or C) (neighbourhood).

4th individual specific argument (street).

Example Climate-For-A: refers to the neighbourhood "CCS is good for the climate", thus a group of arguments Climate-For-A1: refers to the street "Together with renewable energy and energy saving, $\mathrm{CCS}$ reduces $\mathrm{CO}_{2}$ emissions fast enough to avoid dangerous climate change." Climate-against-B-2: refers to the street "CCS can make us lose sight of the urgent need for energy saving and renewable energy."

\section{Reflection on the arguments}

In this section we will reflect on the arguments that are mentioned in Fig. 2 from the top to the bottom, starting on the left side. Unfortunately it is not possible to address all 57 arguments in detail in one paper. Therefore we will discuss the arguments grouped on the neighbourhood level and discuss only a few arguments individually. We end each argument with the conclusion whether it is valid and for which configurations.

\subsection{Climate-related arguments}

\section{CCS is good for the climate (climate-For-A)}

This is a key argument for CCS. Although it represents a generic argument and is therefore valid for all different CCS chains, multiple configurations are needed to contribute significantly to climate mitigation. For example, when Dutch onshore storage locations remain excluded for storage, the potential contribution of CCS is reduced by more than 50\% (Vosbeek and Warmenhoven, 2007). Supporters of this argument state that renewable energy and/or energy efficiency alone are not capable of realising a reliable and economic energy system that will meet the necessary $\mathrm{CO}_{2}$ cuts before 2050. They do not exclude renewable energy or energy efficiency, but consider CCS as an "and-and" solution rather than an "or-or" solution.

In addition to using this argument in a general manner, it is often also referred to in specific applications for industries that do not have access to suitable alternatives, such as the iron and steel industry.

A special configuration of CCS is related to biomass, as this combination gives an option for a negative emission, or in other words enables the extraction of $\mathrm{CO}_{2}$ from the atmosphere. Some scientists consider the agreed $2{ }^{\circ} \mathrm{C}$ increase in comparison with pre-industrial levels insufficient to avoid dangerous climate change. They also point out that a $450 \mathrm{ppm}$ concentration of $\mathrm{CO}_{2}$ in the atmosphere is still too high. They therefore share the opinion that not only deeper cuts in emissions are required, but that $\mathrm{CO}_{2}$ should also be retracted from the atmosphere to stay within safe limits of climate change (Azar et al., 2010). The combination of biomass and CCS is one of the few technologies that can extract $\mathrm{CO}_{2}$ from the atmosphere.

Conclusion: Valid for all different CCS configurations.

CCS makes international climate agreements (more) feasible (climate-For-B)

CCS supports the prospect that the climate target can perhaps be reached without major changes in the energy system for the short- and midterm time horizons. Consequently, this seems an easy way out for countries that are very dependent on fossil fuels. Even though they have to pay for CCS, it will still be easier and more economic than transforming their whole economy and energy system.

For countries like China, US, Russia and Australia that are fossil fuel producers with extensive coal reserves, CCS is a more attractive option than a ban on coal. With this approach they do not have to depreciate their fossil fuel reserves. Interestingly, some environmentalists condemn this as a doom scenario for extending the fossil fuel era. They therefore interpret this pro argument as a strong argument against CCS (see Section 5.2 where energy-related arguments are discussed).

Conclusion: Valid for all different CCS configurations.

CCS is unnecessary for the climate problem (Climate-Against- $A$ )

CCS opponents often point at the enormous potential for energy saving and renewable energy. They state that CCS is therefore unnecessary: renewable energy and energy saving can contribute enough to avoid dangerous climate change. IPCC (2012) compared over 164 different scenarios in more than 1000 pages. The range of $\mathrm{CO}_{2}$ emissions is enormous form virtual zero to over 80 Gtonne $\mathrm{CO}_{2}$ /year. So discussing this argument is at least worth a paper itself. We refer only to two scenarios, from both sides of the range. The first one is from the IEA, representing the argument that CCS is needed. The other one is commissioned by WWF as a provocative scenario to show that $100 \%$ renewable energy is possible in 2050.

In the reference scenario of the IEA (2010) $\mathrm{CO}_{2}$ emissions grow to 57 Gtonne in 2050 , which is about double the current emission. Their blue map scenario aims to halve off the current $\mathrm{CO}_{2}$ emissions in a cost effective way, to $14 \mathrm{Gtonne} \mathrm{CO}_{2} /$ year in 2050. CCS contributes $8 \mathrm{Gtonne} \mathrm{CO}_{2}$ to this reduction. When $\mathrm{CCS}$ is excluded they report an emission of $18 \mathrm{Gtonne} \mathrm{CO}_{2} /$ year. In other words, the use of other technologies can only partly fill in the gap that the exclusion of CCS caused. They are clear about the need for CCS in the industrial sector. "Without CCS, direct emissions in 2050 could only be brought back to current levels. Urgent action is needed to develop and demonstrate CCS applications in industry."

At the other end of the spectrum, the $100 \%$ renewable scenario of $W W F(2011)$ is probably the most ambitious one for $\mathrm{CO}_{2}$ reduction. They report a worldwide reduction of emissions from fossil fuels to $2 \mathrm{Gtonne} \mathrm{CO}_{2}$ /year. $\mathrm{CCS}$ is excluded because, according to the report, by the time CCS could be deployed on a large scale, the use 


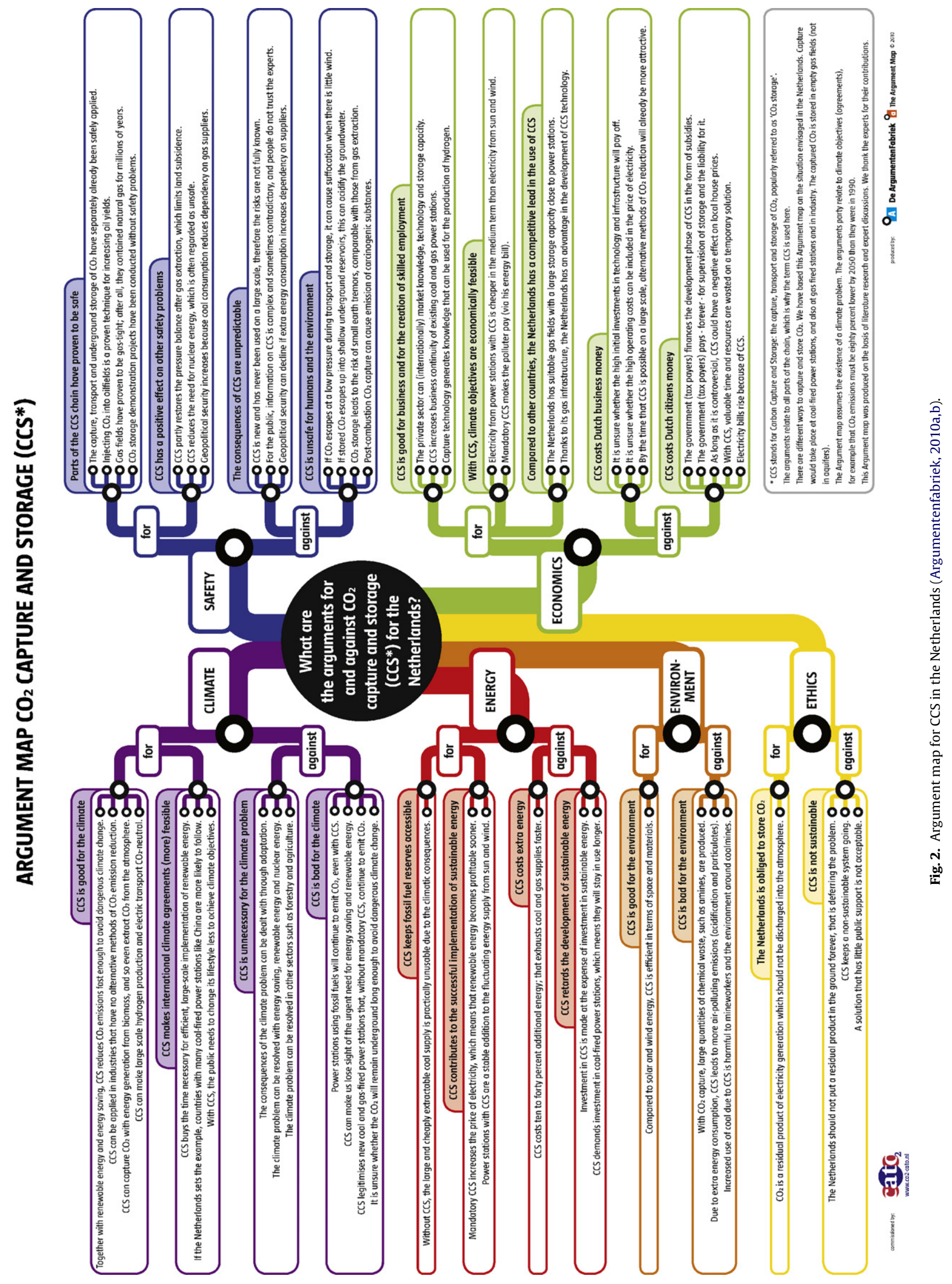


of fossil fuels will have declined so heavily that investments would not be likely to yield the required returns.

In the Netherlands several NGOs including WWF and Greenpeace made a low carbon energy scenario. Their scenario included CCS (Green4sure, 2007).

Conclusion: Some scenarios indicate that CCS is superfluous to reach large reductions in carbon emissions, most scenarios indicate that CCS is necessary, especially in the industrial sector.

$C C S$ is bad for the climate (Climate-Against- $B$ )

This neigbourhood of arguments states that CCS will not help to reduce $\mathrm{CO}_{2}$. In this line of reasoning Greenpeace (2008) calls CCS false hope. The individual streets of this neighbourhood are discussed below.

Power stations using fossil fuels will continue to emit $\mathrm{CO}_{2}$, even with CCS (Climate-Against-B-1)

When $\mathrm{CO}_{2}$ needs to be captured from a diluted source, often not all $\mathrm{CO}_{2}$ is captured. This varies between technologies and the willingness to pay. Systems are generally economically optimised for the lowest cost per avoided tonne $\mathrm{CO}_{2}$, not for the removal of all $\mathrm{CO}_{2}$ in the flue gas. Since high costs are needed to capture the remaining last part, the capture ratio in practice is around $80-90 \%$ for power plants (IPCC, 2005). IEAGHG, 2006 showed that the cost for capturing the last remnants of $\mathrm{CO}_{2}$ reaches exponential heights for post combustion, whereas the incremental costs for oxy-fuel applications are only moderate. New approaches to reach higher capture rates have been proposed. Kunze and Spliethoff (2012), for example, claim that it should be possible to reach 99\% capture at coal gasification power plants with new technology for reasonable prices. For industrial processes, a range has been reported from $60 \%$ to $80 \%$ (IPCC, 2005). For high concentration sources, there are no extra steps required to capture $\mathrm{CO}_{2}$, making it quite feasible. However, for most other cases, even with $\mathrm{CCS}, \mathrm{CO}_{2}$ is still emitted. Another issue is the indirect emission caused by the extra energy needed for capture. This life cycle approach is discussed in Section 5.3. The ROAD project has a capture rate of $90 \%$ (Haskoning, 2011).

Conclusion: Valid for the application 'electricity' with current capture technology.

CCS legitimises new coal and gas-fired power stations that, without mandatory CCS, continue to emit $\mathrm{CO}_{2}$ (Climate-Against-B-3)

Around 2007 several plans for new coal-fired power plants were presented in the Netherlands. The Dutch government did not deem it possible to make CCS mandatory for these power plants. However, they did state that the new coal-fired power plants should be "capture ready". The minister also pointed out that the power plants fall under the European Emission trade scheme and that companies therefore have an economic incentive to emit less $\mathrm{CO}_{2}$. She therefore concluded that the new power plants were not in contradiction with the ambitious climate policy (TK, 2007). This leads to the argument that CCS technology provides developers of coal-fired power plants with the argument that low carbon electricity production is possible but that the actual sequestration of $\mathrm{CO}_{2}$ is uncertain.

Conclusion: Valid for the application 'electricity'.

It is unsure whether the $\mathrm{CO}_{2}$ will remain underground long enough to avoid dangerous climate change (climate-against- $B-4$ )

This is more or less a generic argument on the step of $\mathrm{CO}_{2}$ storage. However, there are differences per reservoir type. From Table 1 it becomes clear that, in general, empty gas fields have the lowest risk of $\mathrm{CO}_{2}$ leakage. The vast majority of studies on potential leakage deal with environmental and human risk rather than climate risk. Although there is a preference for storage sites with characteristics that will not allow any leakage, no guarantees can be given that the stored $\mathrm{CO}_{2}$ cannot ever enter the atmosphere again.

van der Zwaan and Smekens (2009) have calculated the maximum allowable leakage of the total $\mathrm{CO}_{2}$ storage portfolio from a climate perspective. They conclude that a leakage rate at or below $0.5 \%$ per year is needed for $\mathrm{CO}_{2}$ storage being an economically competitive carbon-free energy option. IPCC (2005) states that for geological storage sites that are selected, designed and managed well, it is very likely that the leakage will be below $1 \%$ per 100 years, and likely to be below $1 \%$ over 1000 years. The maximum expected leakage will thus be at least a factor 50 lower than needed from a climate perspective. These leakage rates are based on expert opinions. Due to the novelty of underground $\mathrm{CO}_{2}$ storage, it is impossible to validate the models behind expert opinions for long time scales empirically. However, a margin of error of a factor 50 is very large.

Conclusion: This argument is unlikely to be valid for the field types that are being considered in the Netherlands.

\subsection{Energy-related arguments}

\section{CCS keeps fossil fuel reserves accessible (Energy-For-A)}

This neighbourhood states that climate is the limiting factor for fossil fuel use instead of the availability of fossil fuels, since the amount of carbon available in fossil fuels outnumbers the amount of carbon that the climate can deal with.

Meinshausen et al. (2009) argue that there is a 50\% chance that the $2{ }^{\circ} \mathrm{C}$ temperature rise target may not be met when cumulative worldwide $\mathrm{CO}_{2}$ emissions over $2000-2050$ are $1440 \mathrm{Gt} \mathrm{CO}$. A considerable part of this 'carbon budget' has already been used. The current worldwide $\mathrm{CO}_{2}$ emissions due to the use of fossil fuels are over $30 \mathrm{Gt} \mathrm{CO}_{2}$ per year, approximately $280 \mathrm{Gt} \mathrm{CO}_{2}$ was emitted during the first decade (Friedlingstein et al., 2010). The remaining carbon budget is thus $1160 \mathrm{Gt} \mathrm{CO}_{2}$.

At the end of 2010, proven oil reserves constituted 1383 billion barrels, representing a potential release of $570 \mathrm{Gtonne}$ of $\mathrm{CO}_{2}$. For natural gas and coal this is $350 \mathrm{GtCO}_{2}$ and $2300 \mathrm{Gt} \mathrm{CO}_{2}$ respectively. The current total proven fossil fuel reserves represent over $3200 \mathrm{Gt}$ $\mathrm{CO}_{2}$ (World Energy Council, 2010a). Furthermore, this is an underestimation of the total amount of fossil fuels in the earth crust. The total amount of resources includes fuels that are less certain to be geologically present and/or have doubtful economic feasibility. With new technology it may become possible to extract these fossil fuels in an economic way as well. A recent example is the development of shale gas. It is estimated that the shale gas potential is two and a halve times larger than the current proven gas reserves, resulting in an extra $870 \mathrm{Gt} \mathrm{CO}_{2}$ (World Energy Council, 2010b). IPCC (2012) estimates that the carbon in the coal resources is about $8000 \mathrm{GtCO}_{2}$. BGR (2009) even report a carbon stock of over $40,000 \mathrm{Gt} \mathrm{CO}_{2}$ in coal resources.

These numbers show that there is an enormous amount of fossil fuels, especially coal. This is a factor 3-40 times higher than can be burned from a climate perspective. CCS can therefore prolong the use of fossil fuels.

Conclusion: This neighbourhood is valid, especially for the fuel type coal.

CCS contributes to the successful implementation of sustainable energy (Energy-For-B)

This argument assumes that fossil fuels are needed in the transition period towards a (non-fossil) sustainable energy system, not only on the short term but also on the longer term when the share of renewable energy becomes large. Energy security (energy demand meeting energy supply, also at peak moments without wind or sun) requires the development of large, efficient and cheap energy storage solutions. Furthermore, the electricity network must be adjusted to cope with the intermittent supply of wind or solar energy. Fossil fuels combined with CCS are not seen as sustainable, but they can buy us some time to solve these current technological challenges. In the literature several authors propose a flexible power supply with CCS. Ludig et al. (2011) show that an electricity system with a large amount of renewable energy and fossil fuel power plant equipped with CCS is flexible enough for a reliable system. Davison (2009) proposes a system of hydrogen production 
with CCS for coal gasification with temporary underground hydrogen storage to increase flexibility. The hydrogen will be used in a flexible gas turbine. Meerman et al. (2011) propose a polygeneration gasification facility with CCS that can produce electricity during peak demand and switches to production of carbon liquids, methanol and urea during non peak demand periods. In a not very strict climate regime, it could also be a strategy to turn off the capture unit during peak demand periods and thus emit extra $\mathrm{CO}_{2}$ for a limited period.

Conclusion: This neighbourhood is valid for the application 'electricity'.

CCS requires extra energy (Energy-Against- $A$ )

This argument assumes that (fossil) fuels should be used in an efficient way. The capture part is the most energy intensity part of the CCS chain. The energy needed to capture $\mathrm{CO}_{2}$ depends mainly on the concentration and pressure of the $\mathrm{CO}_{2}$ in the gas stream. IPCC (2005) gave a range of the so-called energy penalty for post combustion at coal fired power plants of $24-40 \%$ for the technology of that time. In the ROAD project it is estimated that $23 \%$ extra energy is needed to capture the $\mathrm{CO}_{2}$ from the new pulverised coal fired power plant. This is just outside the low end of the range (Haskoning, 2011). The CCS energy penalty for new coal power plants based on gasification is lower (about 19\%) according to IPCC (2005), and for new gas fired plants it is about $16 \%$. When $\mathrm{CO}_{2}$ capture is applied at existing power plants, the energy penalty is significantly higher.

The $\mathrm{CO}_{2}$ concentration in flue gases in the steel and cement industry is higher than for power plants, hence the energy penalty will probably be lower. We observed that the methodology of the extra energy needed for the same output is not common in these sectors. Often only the amount of energy needed per tonne capture $\mathrm{CO}_{2}$ is reported. In a workshop organised by IEAGHG (2011) for example, many presentations were given on $\mathrm{CO}_{2}$ capture at the steel industry. Several participants reported extra energy consumption in the range $2-3 \mathrm{GJ} /$ tonne $\mathrm{CO}_{2}$ for blast furnace. They however did not translate this to the extra energy needed for the same amount of produced steel. It is therefore difficult to compare the extra energy needed between these different applications (steel industry and electricity).

For high concentration $\mathrm{CO}_{2}$ sources, e.g. from hydrogen and ammonia plants, the $\mathrm{CO}_{2}$ only has to be compressed. In the proposed Barendrecht case only $5 \%$ extra $\mathrm{CO}_{2}$ was needed for the compression and the transport of the $\mathrm{CO}_{2}$. This means that the net stored $\mathrm{CO}_{2}$ would be $95 \%$ of the $\mathrm{CO}_{2}$ that is captured from the refinery in Pernis (Shell, 2008). A special case is the treatment of natural gas, for instance the K12-B project. This process is already at high pressure and therefore needs even less energy for the whole CCS chain.

Conclusion: This neighbourhood is valid, in particular for the application 'electricity'. It is not true for CCS from high concentration $\mathrm{CO}_{2}$ sources: there, the extra energy needed is quite small.

CCS retards the development of sustainable energy (EnergyAgainst-B)

This argument can be discussed in several ways. The first approach is to look at it from a general perspective on climate targets. When CCS contributes to lower emissions, there obviously is less need for renewable energy to meet the same targets, and in this way CCS retards the development of renewable energy. This argumentation is valid under the assumption that renewable energy can reduce enough $\mathrm{CO}_{2}$ from a climate perceptive without CCS. However, the validity of this assumption is still debated especially in the industry applications (see the argument CCS is unnecessary for the climate problem).

The second approach is to describe where CCS is in direct competition with renewable energy.
CCS and renewable energy, such as solar and wind energy, compete with each other mainly in the application electricity. There, both options can deliver low carbon electricity. However, for several industrial processes feedstock is needed, e.g. in the steel industry. In that case CCS does not compete with solar or wind energy. Biomass could be a renewable alternative in this case.

Conclusion: Valid, in particular for the application 'electricity'. For other applications, it is also valid for the fuel type biomass.

\subsection{Environment-related arguments}

CCS is good for the environment (Environment-For-A)

CCS is bad for the environment (Environment-Against- $A$ )

In this section we discuss the impact of CCS on the environment for the non greenhouse gas emissions. Many studies have conducted Life Cycle Analyses (LCA) of CCS in the power sector (Koornneef et al., 2008; Singh et al., 2011; Zapp et al., 2012). These studies compare the direct en indirect emissions of power plants with and without CCS. The results are more or less similar: almost all emissions, except naturally $\mathrm{CO}_{2}$, increase with CCS during the whole life cycle. The main cause for the extra indirect emissions is the extra energy needed for capture, and therefore the environmental impact of CCS is the biggest in the power sector and other relatively low concentration $\mathrm{CO}_{2}$ streams. The amount of these extra indirect emissions depends on the energy penalty for capture, on the technology used and on the choice of fuel.

Some comments can be made about this LCA methodology. The first is that the total emissions with and without CCS are compared. However, they do not calculate the actual environmental impact since that is not usually taken into account in a LCA. The impact of greenhouse gasses is global, but the impact of human toxicity, for example, strongly depends on the location of the emission. Manuilova et al. (2009) compared the LCA and an Environmental Impact Assessment (EIA) for a CCS case study in Canada. Even when the impacts are known it remains a matter of taste which topic is more important: for example climate change, ozone depletion or acidification.

A second comment is that local decision makers and inhabitants are often more interested in the local environmental impact rather than in the complete life cycle. An environmental impact assessment has been carried out for the ROAD project (Haskoning, 2011). In this assessment the direct emissions from the capture plant are analysed. In the ROAD project about a quarter of the flue gasses of the coal fired power plant are treated in the capture plant. The capture process results in a $\mathrm{CO}_{2}$ reduction of $90 \%$. At the same time no $\mathrm{SO}_{2}$ is emitted, and the emission of particle matters is reduced by half. However, the emission of ammonia and hydrocarbons increased. Also a large amount of amines (MEA) is emitted. The emission of nitrosamines is discussed in Section 5.5. In other words, there are both positive and negative effects on the local environment.

Conclusion: Valid for many applications. Apart from $\mathrm{CO}_{2}, \mathrm{CCS}$ generally causes more emissions during the whole life cycle. From a local perspective some environmental benefits are possible but there may also be higher environmental impacts on other topics. The impact is small when high concentration $\mathrm{CO}_{2}$ streams are used.

\subsection{Ethics-related arguments}

The Netherlands is obliged to store $\mathrm{CO}_{2}$ (Ethics-pro-A)

It is difficult to judge ethical arguments since they can be analysed for internal consistency, but they cannot be verified or falsified empirically. The background of this argument is the assumption that $\mathrm{CO}_{2}$ needs to be stored in order to avoid dangerous climate change. This is the flipside of the debated argument (mentioned earlier in Section 5.1) that CCS is unnecessary for the climate 
problem (Climate-Against-A). There, we concluded that most scenarios show that CCS is indeed required to make deep CO2 emissions cuts.

Conclusion: Valid

CCS is not sustainable (Ethics-against- $A$ )

Even its advocates regard CCS with fossil fuels as a temporary measure to reduce $\mathrm{CO}_{2}$ emissions until renewable energy and energy saving can fulfil our low carbon energy needs without CCS. Since fossil fuel reserves are limited, although their total amount is debated (see Section 5.2), the time span for CCS with fossil fuels is limited to centuries. From this perspective CCS with fossil fuels is not sustainable. It is more difficult to classify CCS combined with biomass.

Conclusion: Valid for all CCS configurations, but perhaps not when the fuel type biomass is used.

A solution that has little public support is not acceptable (ethicsagainst- $A-3$ )

This is an opinion masquerading as an argument and therefore more difficult to test in terms of validity. However, it is interesting to examine public support in order to assess the scope of this argument. Literature points out that it may be necessary to distinguish between general support and local support in order to assess the validity of this argument. Paukovic et al. (2011) asked the Dutch public in a survey to rate several energy options on a ten point scale. Energy saving and wind energy were evaluated best with a 7.5. The option "Large power plants where coal or gas is converted into electricity with CCS" was graded with a 5.0. The other CCS option "Large plants where natural gas is converted into hydrogen with CCS" got a slightly better mark of 5.9. The first CCS option was called unacceptable by $15 \%$, the latter by $5 \%$. CCS applied at gas treatment and steel industry were not included as options in the survey. During this survey the storage location was not mentioned. The general public is thus not enthusiastic about CCS. Their opinion depends in some part on the application where CCS is carried out.

Daamen et al. (2010) did a survey among the population of Barendrecht during the heat of debate on the $\mathrm{CO}_{2}$ project that planned onshore storage in that area. $86 \%$ of the respondents said that the project was unacceptable. Although the layout of this survey and the above surveys were not identical, it is clear that there is a major difference between the verdict 'unacceptable' by around $10 \%$ of the general public and the same verdict by almost $90 \%$ of the local Barendrecht population. The $\mathrm{CO}_{2}$ storage at the offshore location K12b in the Dutch North Sea met no public resistance at all. The actual support or lack of support thus depends strongly on the location and is also influenced slightly by the application. This makes it difficult to assess local support before the start of a project.

Conclusion: Even when local public support for a project is minimal, there may be important reasons that outweigh lack of local support, like meeting climate targets. In that case it is possible that general support, represented by national politics, can outweigh the lack of local support. More generally, the argument is hard to refute or support with facts because the argument expresses an opinion.

\subsection{Safety-related arguments}

The parts of the CCS chains have proven to be safe (Safety-for-A) The consequences of CCS are unpredictable (Safety-Against- $A$ )

Opponents and advocates of CCS often discuss whether CCS is proven technology or not and link this to the safety of CCS. Apart from the safety risk, unproven technology is of course also an economic risk. To a large extent this is a semantic discussion since CCS is an umbrella term for many technologies. Almost all different components of CCS have been demonstrated, although on different scales and circumstances. On the other hand only a few complete
CCS chains have been demonstrated on industrial scale. It is therefore more useful to discuss the track record of the components.

\section{Capture}

$\mathrm{CO}_{2}$ has been captured at industrial processes for almost a century. In most cases this is done to meet process demands and not for storage purposes (IPCC, 2005). Natural gas purification is done on a commercial basis, with various amines solvents that are comparable to those foreseen for post combustion capture. However, the process circumstances for natural gas sweetening are different. That process is under high pressure and with no $\mathrm{NO}_{x}$ or $\mathrm{SO}_{2}$ present. There have been no applications for $\mathrm{CO}_{2}$ capture at large-scale power plants of several hundred megawatts. Other gas cleaning technologies for power plants are common practice, for instance for $\mathrm{NO}_{x}$ and $\mathrm{SO}_{2}$. For the production of hydrogen, similar processes to pre combustion are widely used and this is considered proven technology. The use of oxy fuel combustion has been demonstrated on pilot scale.

\section{Transport}

$\mathrm{CO}_{2}$ has been transported for decades to EOR projects, mainly in the US and Canada. There are more than $2500 \mathrm{~km}$ of pipelines transporting $\mathrm{CO}_{2}$ from natural and industrial sources (IPCC, 2005). The Netherlands has over $200 \mathrm{~km}$ of $\mathrm{CO}_{2}$ pipelines for greenhouses (OCAP, 2007). The experience with $\mathrm{CO}_{2}$ transport by ship is limited. Worldwide there are only a few small ships in use to transport liquefied foodgrade $\mathrm{CO}_{2}$ (IPCC, 2005). $\mathrm{CO}_{2}$ transport by ship has a number of similarities to commercial liquefied petroleum gas (LPG) transportation by ship, but there are also some differences due to the properties of $\mathrm{CO}_{2}$.

\section{Storage}

The injection of $\mathrm{CO}_{2}$ in oil fields for EOR has been done for decades in USA. Apart from the injection in oil fields there are three industrial scale projects operational today, two in Norway and one in Algeria. These projects all store the $\mathrm{CO}_{2}$ in deep subsurface aquifers (GCCSI, 2011a,b). In the Netherlands Gaz de France-Suez has been injecting $\mathrm{CO}_{2}$ in an offshore gas reservoir since 2004. Worldwide, there are other smaller storage projects like the Recopol-project where $\mathrm{CO}_{2}$ is injected in coal layers in Poland.

Underground natural gas storage projects have been operated successfully for almost 100 years (IPCC, 2005). There is also experience with the seasonal storage of town gas, for example at Ketzin, Germany where no $\mathrm{CO}_{2}$ is stored (Co2sink, 2012). With these projects a knowledge base has been developed for geological models with injection rates and storage capacity. This also created a lot of experience in operating the injection of a gas. There is a chemical difference between natural gas and $\mathrm{CO}_{2}$. The latter can react with minerals in the reservoir, as well as with the cement that is used to fill the injection well when this is abandoned.

Conclusion: Many different components of the CCS chain have been demonstrated on different scales. Also, some similarities with other processes are known. However, the experience with complete CCS chains in the electricity sector is very limited. The experience and also the occurrence of unexpected situations are thus depending on the specific CCS chain. So, both arguments are valid depending on the specific CCS chain.

CCS has a positive effect on other safety problems (Safety-For-B)

CCS clears the way to use more coal under a strict climate regime. The geographical distribution of coal is larger than for oil and gas (World Energy Council, 2010a). When more coal is used, this could lead to less dependence on for example the Middle-East and Russia, thus increasing geopolitical security. For the midterm, the substitution of coal is limited to the power sector as the transport sector is based on oil and heating is based on natural gas. On the longer term, one could propose the conversion of coal to liquids and/or gas 
combined with CCS, making the application broader than the electricity sector. Coal combined with CSS could also be an alternative for nuclear power that is sometimes regarded as unsafe.

Conclusion: Valid for the application 'electricity'.

CCS is unsafe for humans and the environment (Safety-Against-B)

The risks of CCS to humans and the environment is often used as an argument against CCS. We discuss some of these arguments in detail.

If $\mathrm{CO}_{2}$ escapes at a low pressure during transport and storage, it can cause suffocation when there is little wind (Safety-Against-B-1).

$\mathrm{CO}_{2}$ can cause suffocation at high concentrations. The impact depends on the duration and concentration of the exposure. For example concentrations above $10 \%$ can cause death when one is exposed for $10 \mathrm{~min}$ (IEAGHG, 2009). The worst case scenario is a $\mathrm{CO}_{2}$ blanket that enters a village. This image was used during the debate on the Barendrecht project (ZEMBLA, 2010). The assessment of the risks of $\mathrm{CO}_{2}$ transport by pipelines is very complicated, see e.g. Koornneef et al. (2010). An important issue is whether the $\mathrm{CO}_{2}$ will mix with the air. When the $\mathrm{CO}_{2}$ is released at a higher pressure it will mix with the air due to its own release velocity. However, when the $\mathrm{CO}_{2}$ is expanded in a closed area, e.g. a tunnel, dangerous concentrations might occur. In the absence of wind, and at the same time the presence of an uneven landscape with hills, ditches etc., there is a minute possibility that a $\mathrm{CO}_{2}$ cloud is formed. These improbable conditions can only occur onshore.

Conclusion: Valid for onshore storage locations only.

Post-combustion $\mathrm{CO}_{2}$ capture can cause emission of carcinogenic substances (Safety-Against-B-4)

A very technology specific debate is on nitrosamines. Nitrosamines are organic compounds that can be released during post combustion processes when amines are used. Nitrosamines have a short lifetime in the atmosphere as they disintegrate after exposure to sunlight. The current debate in literature focuses on the impact of nitrosamines and the lifetime of nitrosamines (ZEP, 2012). In the ROAD project nitrosamines will be formed as well. According to the environmental impact assessment of the project there are "sufficient safeguards to ensure that there will not be any harmful effects" (Haskoning, 2011).

Conclusion: Valid for specific post-combustion capture technologies.

\subsection{Economy-related arguments}

CCS is good for business and for the creation of skilled employment (Economy-For-A)

Compared to other countries, the Netherlands has a competitive lead in the use of CCS (Economy-For-C)

In this section we discuss these two neighbourhoods together since they both argue that CCS will be beneficial to the Dutch economy. The Netherlands has a long tradition on CCS research and is among the word leaders in this field (van Egmond et al., in press). It is difficult to judge whether this knowledge base will have a large impact on the Dutch economy. The Netherlands is also well located for becoming a $\mathrm{CO}_{2}$ hub. Half of the emissions of large stationary sources are within a $500 \mathrm{~km}$ range. The Netherlands and the neighbouring North Sea, especially in the Norwegian waters, have large $\mathrm{CO}_{2}$ storage capacity. Combined with the long Dutch tradition in gas transport and trading, as well as in offshore activities, this puts the Netherlands in a good position to become the $\mathrm{CO}_{2}$ hub of North West Europe (Platform Nieuw Gas, 2007). So one may indeed argue that CCS could generate business for the Netherlands, but the claim "competitive lead" is exaggerated since very few businesses have intentions to make money with CCS (van Alphen, 2011). A good starting position is perhaps a better description.
Conclusion: Partially true. The starting position of the Netherlands is good. However, the economic benefits can only materialise if these advantages are put to good use.

With CCS, climate objectives are economically feasible (EconomyFor- $B$ )

The background of this argument is that a low carbon economy is cheaper with CCS than without CCS. ECN/MNP (2007) confirm that the cost for meeting the Dutch climate goals in 2020 for the whole energy system with CCS is $€ 3.5$ billion versus $€ 8$ billion when CCS is excluded. The scenarios of IEA that reduce $\mathrm{CO}_{2}$ emissions for the power sector in 2050 by $90 \%$ also establish that excluding CCS will lead to higher prices electricity prices, $38 \%$ without versus $18 \%$ with CCS compared to the baseline (IEA, 2010). On the other hand, WWF (2011) report that their low carbon scenario without CCS is costeffective and will provide energy that is affordable for all. They do not compare the cost of the energy system with and without CCS.

Conclusion: This neighbourhood of arguments is debated.

CCS costs Dutch business money (Economy-Against- $A$ )

$C C S$ costs Dutch citizens money (Economy-Against- $B$ )

The previous argument stated that a low carbon economy with CCS is less expensive than a low carbon economy without CCS. This may be true, but CCS costs money as well. As capture is the most expensive step of the CCS chain, the cost of CCS will to a large extent be determined by the application. GCCSI (2011b) gives very wide cost ranges. Capture costs from ammonia production and natural gas sweetening are about $20 \$ /$ tonne $\mathrm{CO}_{2}$. For steel and cement $54 \$ /$ tonne $\mathrm{CO}_{2}$ is reported, whereas for power plants a range of 44-107\$/tonne $\mathrm{CO}_{2}$ is given. The wide spread of the range for power plants can be explained by the lack of large scale examples for $\mathrm{CO}_{2}$ capture at power plants. The price of an EU allowance is currently below $10 € /$ tonne (Point Carbon, 2012). The Deutsche Bank expects that the price could rise in 2020 towards $20-25 € /$ tonne (Reuters, 2011), still far below the cost of CCS.

In other words: CCS costs money. An important question is who is going to pay for this: either the tax payer or the polluter. NGOs are against government subsidy for CCS (e.g. Greenpeace, 2008). If the polluter has to pay for CCS, he will pass on the extra cost to his end users, for instance by raising the electricity prices. In both cases the Dutch citizens will have to pay for CCS.

An exception to this may be the case where $\mathrm{CO}_{2}$ is used to produce extra oil or gas. Enhanced oil recovery has been done commercially for decades. However, the Netherlands has only 10 oil fields in production (TNO, 2011). Enhanced gas recovery might also be interesting. An example is the offshore demonstration project at the $\mathrm{K} 12 \mathrm{~b}$ field.

On the other hand, climate change costs money as well. Stern (2006) for example estimated that a $2-3{ }^{\circ} \mathrm{C}$ temperature rise will result in a loss of $0-3 \%$ of the world's output. A temperature rise of $5-6{ }^{\circ} \mathrm{C}$ could even lead to a loss of 5-10\% global GDP. However this paper assumes that there is a climate change policy with strict targets. So doing nothing does not lie within the scope of the inventory and analysis of the arguments.

Conclusion: Valid, with some exceptions for EOR and EGR.

\section{Discussion and conclusion}

In the previous section we have analysed the arguments for and against CCS. We concluded that most of these arguments are valid but often only apply to specific configurations. Some of the arguments are controversial.

Obviously some arguments are stronger and more relevant than others. However, it is almost impossible to rank the arguments since the importance of an argument will differ from one person to another. For example the argument "CCS retards the development 
of sustainable energy" is crucial for people who want to end the fossil era as quickly as possible. For those who are of the opinion that climate and environmental targets should be met, regardless the route, this is an irrelevant argument.

\subsection{Interaction between arguments}

The arguments have been discussed separately in this paper; however in a debate arguments are interrelated. We will give one example of the interaction between several energy arguments. As shown in Section 5.2, the argument against CCS because of the extra amount of energy that is necessary for several CCS chains is legitimate for certain configurations. However, one may wonder whether it is a relevant argument, as it is set against the argument for CCS that there is no other way for fossil fuels to be used due to the global carbon budget. In other words, the climate is the limiting factor for the use of fossil fuels and not the supply of fossil fuels. The use of extra energy has other impacts on cost and environmental effects as well, but those are different arguments.

\subsection{Applicability of the presented arguments}

The presented categorisation of arguments and their scope may contribute to a better informed debate. However, we realise that the presented arguments are still rather technical and far away from the perception of a local resident of a storage location. He may for example use the phrase "I just do not want $\mathrm{CO}_{2}$ under my backyard". This legitimate statement is more an opinion than a proposition for debate. Perhaps the reasons for his statement are based on the presented arguments and/or other (true or false) facts. The map presented here is therefore more useful for the CCS community and policy makers as a tool to improve their considerations on future energy systems.

A next step in using these arguments is to relate the arguments to the world views of people, organisations and political parties since opinions consist of a coherent set of arguments. For example, a person with great trust in science and technology would use another set of arguments to come to a conclusion on CCS than a person with great distrust in science. Also, it seems logical that a person who, for example, is in favour of nuclear energy and accepts safety models on nuclear risks, will also accept comparable analyses on $\mathrm{CO}_{2}$ storage.

In reality, discussions are of course not always based on facts. Arguments may also be used strategically or opportunistically, or in a combination of arguments. The set of arguments presented in this paper may also be used to analyse the consistency and quality of the arguments used and thereby improve the quality of the societal debate on CCS.

\section{Acknowledgements}

This research has been carried out in the context of the CATO2-program. CATO-2 is the Dutch national research program on $\mathrm{CO}_{2}$ Capture and Storage. The program is financially supported by the Dutch government (Ministry of Economic Affairs) and the CATO-2 consortium parties. We also thank the Argument Factory for their contributions in the collection and grouping of the arguments. Several researchers of the CATO programme, like Jan Brouwer (CATO/TNO), Joris Koornneef (Ecofys) and Daniel Jansen (ECN) have been willing to share their thoughts on the scope of the different arguments. Finally we would like to thank Marlies Verlinde for text editing.

\section{References}

Arentsen, M.J., 2006. Contested technology, nuclear power in the Netherlands. Energy \& Environment $17,3$.

Argumentenfabriek, 2010a. Argument map $\mathrm{CO}_{2}$ capture and storage (CCS), Argumentenfabriek, Amsterdam, 2010.

Argumentenfabriek, 2010b. Personal communication with Kalshoven, F., director argument factory, 23 April 2010.

Azar, C., Lindgren, K., Obersteiner, M., Riahi, K., van Vuuren, D.P., den Elzen, K.M.G.J., Möllersten, K., Larson, E.D., 2010. The feasibility of low $\mathrm{CO}_{2}$ concentration targets and the role of bio-energy with carbon capture and storage (BECCS). Climatic Change 100, 195-202.

BGR, 2009. Energy Resources 2009 - Reserves, Resources, Availability. Federal Institute for Geosciences and Natural Resources, Hannover, Germany.

CATO, 2011. www.co2-cato.nl (01.12.11).

Co2sink, 2012, www.co2sink.org/techinfo/hse.htm (07.08.12).

Daamen, D., Terwel, B., ter Mors, M., 2010. Wat weten en vinden Barendrechters van het $\mathrm{CO}_{2}$ opslag plan en van voorlichting en besluitvorming over dit plan? Leiden University, Leiden, The Netherlands.

Davison, J., 2009. Electricity systems with near-zero emissions of $\mathrm{CO}_{2}$ based on wind energy and coal gasification with CCS and hydrogen storage. International Journal of Greenhouse Gas Control 3, 683-692.

De Coninck, H., Flach, T., Curnow, P., Richardson, P., Anderson, J., Shackley, S., Sigurthorsson, G., Reiner, D., 2009. The acceptability of $\mathrm{CO}_{2}$ capture and storage (CCS) in Europe: an assessment of the key determining factors. Part 1. Scientific, technical and economic dimensions. International Journal of Greenhouse Gas Control 3, 333-343.

De Jong, K.P., 2010. Personal communication during 5th Dutch CCS conference, 25 June 2010, Utrecht.

De Vos, R., van Egmond, S, 2010. GHGT Times, Daily bulletin of the 10th Conference on Greenhouse Gas Control Technologies, Amsterdam RAI, 22 September 2010

Ecn/Mnp, 2007, Verkenning potentieel en kosten van klimaat en energiemaatregelen voor Schoon en Zuinig, Petten.

Fd, 2007. Shell Nederland verhoogt investeringen, in Financiele dagblad (FD), op het veld, R., 8 May 2007.

Friedlingstein, P., Houghton, R.A., Marland, G., Hackler, J., Boden, T.A., Conway, T.J., Canadell, J.G., Raupach, M.R., Ciais, P., Le Quere, C., 2010. Update on $\mathrm{CO}_{2}$ emissions. Nature Geoscience 3, 811-812.

GCCSI, 2011a. The Global Status of CCS: 2010. Global CCS Institute, Canberra, Australia.

GCCSI, 2011b. Economic Assessment of Carbon Capture and Storage Technologies: 2011 update, Canberra, Australia.

Green4sure, 2007. Het groene energieplan, F.J., Rooijers, B.H., Boon, J. Faber et al. CE Delft, Delft, the Netherlands.

Greenpeace, 2008. False Hope - Why Carbon Capture and Storage Won't Save the Climate. Greenpeace International, Amsterdam, the Netherlands.

Haskoning, 2011. Milieueffectrapportage CCS Maasvlakte (ROAD project), Deelrapport Afvang, Royal Haskoning, Nijmegen, The Netherlands.

IEA, 2010. Energy Technology Perspectives 2010 Scenarios and Strategies to 2050. OECD/IEA, Paris, France.

IEAGHG, 2006. Near zero emission technology for $\mathrm{CO}_{2}$ capture from power plants, 2006/13, Cheltenham, UK

IEAGHG, 2009. Safety in Carbon Dioxide Capture and Storage, Cheltenham, UK.

IEAGHG, 2010. 1st Meeting of the Social Research Network, 2010/9, June, Cheltenham, UK.

IEAGHG, 2011. Challenges and Opportunities of $\mathrm{CO}_{2}$ Capture and Storage for the Iron and Steel Industry, 17, December 2011, Cheltenham, UK.

IPCC, 2005. Special report on carbon dioxide capture and storage. In: Metz, B., Davidson, O., de Coninck, H., Loos, M., Meyer, L. (Eds.), Prepared by Working group III of the Intergovernmental Panel on Climate Change. Cambridge University Press, Cambridge, UK.

IPCC, 2012. Renewable energy sources and climate change mitigation. In: Special Report of the Intergovernmental Panel on Climate Change. Cambridge University Press, New York, USA.

Kliest, A., 2010. Beeldvorming over $\mathrm{CO}_{2}$ afvang en opslag, M.Sc., Thesis, Faculty of Geosciences, Utrecht University.

Koornneef, J., van Keulen, T., Faaij, A., Turkenburg, W., 2008. Life cycle assessment of a pulverized coal power plant with post-combustion capture, transport and storage of $\mathrm{CO}_{2}$. International Journal of Greenhouse Gas Control 2 , 448-467.

Koornneef, J., Spruijt, M., Molag, M., Ramírez, A., Turkenburg, W., Faaij, A., 2010. Quantitative risk assessment of $\mathrm{CO}_{2}$ transport by pipelines-a review of uncertainties and their impacts. Journal of Hazardous Materials 177 (1-3) $12-27$.

Kunze, C., Spliethoff, H., 2012. Assessment of oxy-fuel, pre- and post-combustionbased carbon capture for future IGCC plants. Applied Energy 94 (0), 109-116.

Ludig, S., Haller, M., Schmid, E., Bauer, N., 2011. Fluctuating renewables in a long-term climate change mitigation strategy. Energy 36, 6674-6685.

Manuilova, A., Suebsiri, J., Wilson, M., 2009. Should life cycle assessment be part of the environmental impact assessment? Case study: EIA of $\mathrm{CO}_{2}$ capture and storage in Canada. Energy Procedia 1, 4511-4518.

Meerman, J.C., Ramirez, A., Turkenburg, W.C., Faaij, A.P.C., 2011. Performance of simulated flexible integrated gasification polygeneration facilities. Part A: A technical-energetic assessment. Renewable and Sustainable Energy Reviews 15, 2563-2587. 
Meinshausen, M., Meinshausen, N., Hare, W., Raper, S.C.B., Frieler, K., Knutti, R., Frame, D.J., Allen, M.R., 2009. Greenhouse-gas emission targets for limiting global warming to $2^{\circ} \mathrm{C}$. Nature $458,1158-1162$.

Nackenhorst, K., Olsthoorn, M., Warmenhoven, H., Soest, van J.P., 2009. $\mathrm{CO}_{2}$ - afvang en opslag: Vijgenblad, noodzakelijk kwaad of wereldkans? - Eindrapport EDN CCS-Dialoog - Stichting Energie Dialoog Nederland, Rotterdam, the Netherlands.

OCAP, 2007. OCAP. $\mathrm{CO}_{2}$ horticultural greenhouse - Factsheet (year estimated), Scheidam, the Netherlands.

Paukovic, M., Brunsting, S., de Best-Waldhober, M., 2011. The Dutch General Public's Opinion on CCS and Energy Transition: Development in Awareness, Knowledge Beliefs and Opinions Related to Information and Media Coverage. ECN, Amsterdam.

Platform Nieuw Gas, 2007. Werkgroep $\mathrm{CO}_{2}$ - opslag/Schoon fossiel, Beleidsrapportage Schoon Fossiel, Utrecht, The Netherlands.

Point Carbon, 2012. www.pointcarbon.com (24.02.12)

Reuters, 2011. Deutsche cuts $2011 \mathrm{EU} \mathrm{CO}_{2}$ price view by a third, 29 November 2011, London.

Shell, 2008. MER Ondergrondse opslag van $\mathrm{CO}_{2}$ in Barendrecht, Deelrapport 2: Beschrijving milieueffecten (beleid, effecten en classificatie per milieuthema), Shell $\mathrm{CO}_{2}$ Storage B.V., Den Haag.

Singh, B., Strømman, A.H., Hertwich, E.G., 2011. Comparative life cycle environmental assessment of CCS technologies. International Journal of Greenhouse Gas Control 5, 911-921.

Stern, N., 2006. The Economics of Climate Change. HM Treasury, London.

TK, 2007. Verslag algemeen overleg Evaluatienota Klimaatbeleid, Tweede Kamer, vergaderjaar 2006-2007, 28 240, nr. 86.

TNO, 2011. Natural resources and geothermal energy in the Netherlands, Annual review 2010, June 2011, Den Haag, The Netherlands.
UNFCCC, 2011. Report of the Conference of the Parties on its sixteenth session, held in Cancun from 29 November to 10, United Nations Framework Convention on Climate Change, December 2010.

van Alphen, 2011. Accelerating the development and deployment of carbon capture and storage technologies: an innovation system perspective, Ph.D. Thesis Utrecht, Netherlands, pp. 90-93.

van der Zwaan, B., Smekens, K., 2009. $\mathrm{CO}_{2}$ capture and storage with leakage in an energy-climate model. Environmental Modelling and Assessment 14, 135-148.

van Egmond, S., Heimeriks, J.G., Brouwer, J., Hekkert, M.P., Gale, J. CATO, the Dutch carbon capture, transport and storage programme a knowledge network, International Journal of Greenhouse Gas Control, in press.

Vosbeek, M., Warmenhoven, H., 2007. Making large-scale Carbon Capture and Storage CCS in the Netherlands WORK. Ecofys, Utrecht, the Netherlands.

World Energy Council, 2010a. 2010 Survey of Energy Resources. London, United Kingdom.

World Energy Council, 2010b. Survey of Energy Resources: Focus on Shale Gas World Energy Council, London, United Kingdom.

WWF, 2011. The energy report, $100 \%$ renewable energy by $2050, \mathrm{WWF} /$ Ecofys/OMA Gland, Switzerland.

Zapp, P., Schreiber, A., Marx, J., Haines, M., Hake, J., Gale, J., 2012. Overall environmental impacts of CCS technologies - a life cycle approach. International Journal of Greenhouse Gas Control 8, 12-21.

ZEMBLA, 2010. Television documentary $\mathrm{CO}_{2}$ bomb under Barendrecht, Driehuis, $\mathrm{K}$. VARA, in 28 March 2010.

ZEP, 2012. Status Review - The Formation Control and Environmental Fate of Emissions from Amine-based $\mathrm{CO}_{2}$ Capture Plants. European Technology Platform for Zero Emission Fossil Fuel Power Plants, Brussels, Belgium. 